\title{
A Fast Transient Response Technique for DPWM DC-DC Converters
}

\author{
Yoichi Ishizuka, Fumitoshi Hirose, Yusuke Yamada and Hirofumi Matsuo \\ Faculty of Engineering \\ Nagasaki University \\ Nagasaki, Japan \\ isy2@nagasaki-u.ac.jp
}

\begin{abstract}
The demand for adaptive and smart power distributing is becoming very popular in the commercial power line such as a smart grid. The information from the load condition is very important for the distributing. To obtain such information from the multiple-load, the digital control for switching mode power supply (SMPS) is effective. Usually, the digital controller is consisted of DSPs or microprocessors performing with software. But, such as for point of load (POL), adapting digital controller isn't still popular because of its cost or response characteristics even if the controllers are constructed by FPGA or custom LSI which is hardware-logic base. This paper will discuss about the proposed hardware logic type digital controller for POL, which is very simple and unique design. And, accuracy improved output voltage detection method for the proposed digital controller is proposed. The some experiments are done. And the results show the validity of the proposed circuits.
\end{abstract}

\section{INTRODUCTION}

Digital electronic products have been spreading quickly by the advancement of the integrations technologies. ICs, DSPs and FPGAs requires a high performance and a high speed due to the trend. Along with the situations, their power consumption are increasing. To suppress the power consumption, the power supply voltage is getting lower toward to sub $1 \mathrm{~V}$. Because of the severe voltage margin by the lower power supply voltages, special SMPS, point of load (POL) is disposed very near to the load. The requirements of POL are relative low output voltage with large output current, high load change response, highefficiency, low cost and etc... Also, the control circuit of POL is required to be high accurate, high speed, adaptive and low cost. We had proposed hardware-logic based digital PWM control circuit is effective to such requirements [1-3]. In this paper, the proposed DPWM control method's principles of operation and circuit configurations are described firstly. At the next, a piecewise linear output voltage detection method is proposed and discussed which can improve the output voltage detection accuracy. Finally, the proposed technique is confirmed with some experiments.

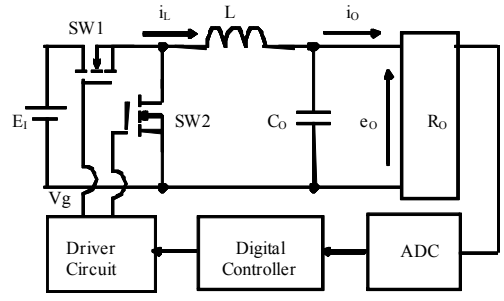

(a) Circuit configuration

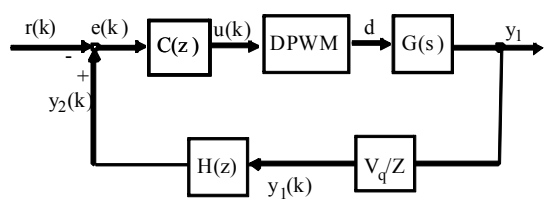

(b)Control block

Fig. 1 General DPWM-POL

II. DPWM CONTROL METHOD FOR POL (DPWM-POL)

The circuit configuration of general DPWM controller for $P O L$

The circuit configuration of general DPWM controller for POL is shown in Fig. 1[4-11]. This topology has two major time-delay problems. First, time-delay occurs at $\mathrm{A} / \mathrm{D}$ converter with the conversion-delay. And, the calculation time of digital controller is another problem. Both of the time-delay directly effects on the response speed of the control circuit and influences stability of the control.

\section{A. The circuit configuration of the proposed DPWM-POL}

Figure 2 shows the main and the control circuit configuration of the proposed DPWM-POL in this research. Main POL circuit is a quite ordinary non-isolated buck converter. The control circuit is composed with $\mathrm{D} / \mathrm{A}$ converter, analog comparator, digital controller and drive circuit. 


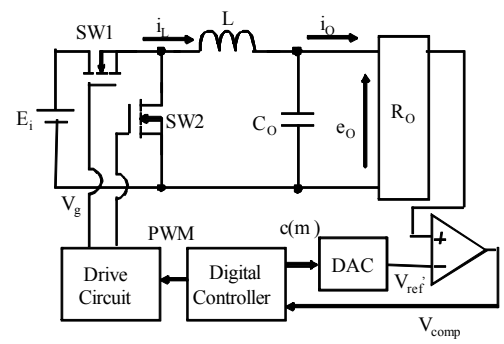

Fig. 2 Circuit configuration of the proposed DPWMPOL

\section{B. The control circuit configuration of the proposed $D P W M-P O L$}

Figure 3 shows the control circuit configuration of the proposed DPWM-POL. All blocks are synchronized with the system clock $f_{C L K}$. Memory1 can store waveform values not only triangle or saw tooth but any waveforms. The output voltage $e_{o}$ of POL is compared with the converted voltage of memoryl's output in the ATC block, successively. The comparator's output is read out to the latch signal to the latch register at the timing that of $e_{o}$ was sensed. And this latch signal is transferred to DPWM output block. And this latch signal is transfer to DPWM output block.

Also, the look-up table method is used for the duty ratio calculation with memory2, 3 and 4 . Especially, the duty ratio information which is pre-calculated is stored corresponding to $e_{o}$, respectively, in memory 2 . The duty ratio information is read out from memory 2 according to $f_{C L K}$. At the timing of $e_{o}$ sensed, one of the duty ratio information is chosen in $D F F_{4}$. And the information becomes $u(k)$, where $k$ is the switching term. At the digital comparator, $u(k)$ is converted to real-time analog PWM waveforms. These precise operation technique is described in [2,3]. Fig. 4 shows the waveform of $V_{r e f}^{\prime}$ and $V_{\text {comp. }}$.

As a result, comparing with a general digital control method, this proposed control technique doesn't need to calculate the duty ratio information in every switching term, and also the conversion time-delay at A/D converter doesn't exist. Therefore, time-delay drastically decreased to just the sum of calling and the loading time of thememory2.

\section{Piecewise Linear Output Voltage Detection Method (PLOVDM)}

This controller can add the improvement in each block respectively. In this paper, the improvement of the output voltage detection accuracy in the ATC block without any cost-up is aimed. D/A converter used in the ATC block assumes the ladder type, and the output voltage $V^{\prime}{ }_{r e f}$ is provided between two potential of $V_{r e f}^{+}=V_{r e f}+\alpha$ and $V_{r e f}$.

$$
V_{r e f}^{\prime}=\frac{c(m)}{2^{n}}\left(V_{r e f}^{+}-V_{r e f}^{-}\right)+V_{r e f}^{-}
$$

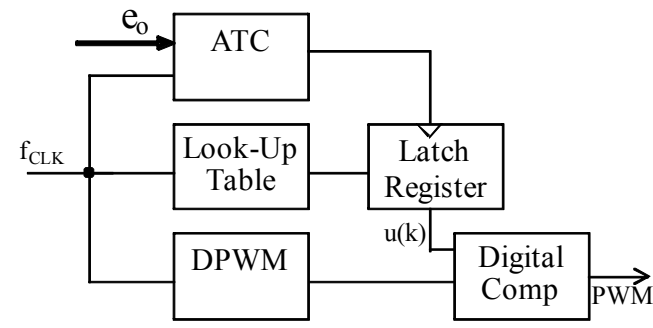

(a) Proposed control circuit blocks

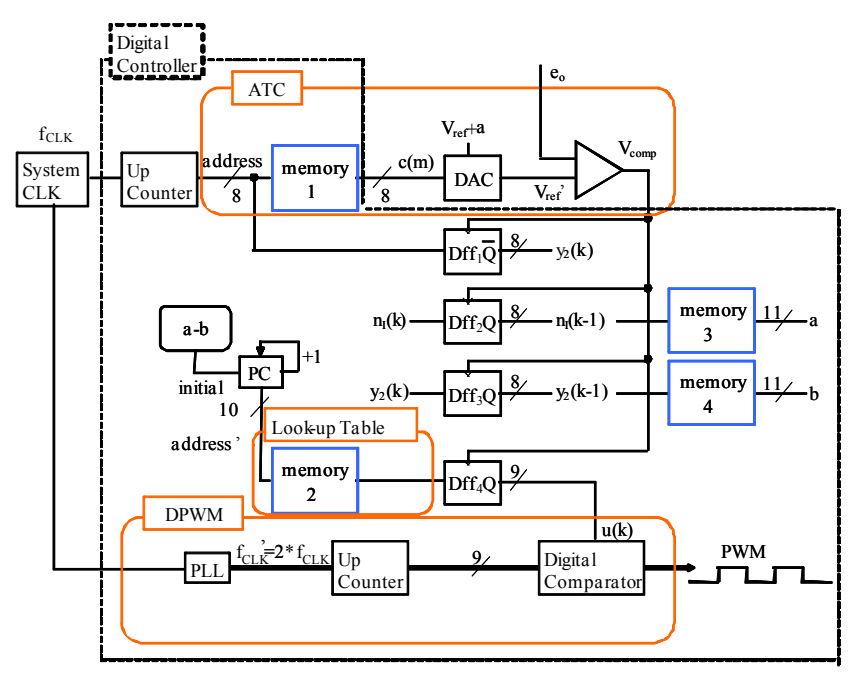

(b) Design descriptions of the control circuit blocks Fig. 3 The system configuration of the part of the proposed control circuit

where $c(m)$ is waveform digital data prestored in memory $1, m$ is clock timing and $n$ is a number of bits. In this time, almost $n+1$ bits accuracy can be achieved by setting as $V_{\text {ref }}=V_{\text {ref }} / 2$ in the $n$ bits system. The detection time will be delay and it will be the trade-off between the accuracy and the time-delay. Therefore, another compensation technique is proposed to solve the trade-off problem. Thanks to the compensation technique, the trade off problem was solved. Precise descriptions will be revealed in proceeding.

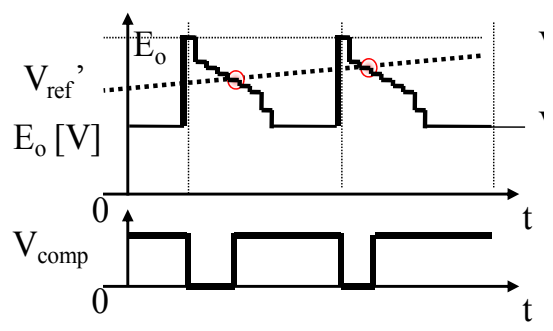

Fig. 4 The waveform of $V^{\prime}{ }_{r e f}$ and $V_{\text {comp }}$ 


\section{EXPERIMENTS}

We have done some experiments with the experiment parameters shown in Table 1. The control parameters can be easily modified by rewriting information in memory 2 . Fig. 5 shows the experimental waveforms. Fig. 6 shows $I_{O}-E_{O}$ characteristics. It shows the deviation becomes within $5 \%$ in the range of the load change when the proportion gain $K_{P}$ was larger than 3 . Fig. 7 shows $E_{I}-E_{O}$ characteristics, where $K_{P}$ is over 5 . The deviation becomes within 10\%. Max power efficiency is about $91 \%$ shown in Fig. 8. Fig. 9 and Fig. 10 shows dynamic characteristic, where the load change between $0.5 \mathrm{~A}$ and $5 \mathrm{~A}$ with $10 \mathrm{~A} / \mu \mathrm{s}$ slew rate condition, respectively. The mixed-signal oscilloscope Textronix MSO4034 is used to measure analog and digital signal, simultaneously. Blue and Red line shows the output voltage and the output current, respectively. The 9 bits

Table. 1 Experiment parameters

\begin{tabular}{|c||c|}
\hline Input voltage $E_{I}$ & $3-8 \mathrm{~V}$ \\
\hline Output reference $V_{r e f}$ & $1.5 \mathrm{~V}$ \\
\hline Output current $I_{O}$ & $0-6 \mathrm{~A}$ \\
\hline Switching frequency $f_{S}$ & $130 \mathrm{kHz}$ \\
\hline Choke inductor $L$ & $10 \mu \mathrm{H}$ \\
\hline Output capacitor $C_{O}$ & $470 \mu \mathrm{F}$ \\
\hline Proportion gain $K_{P}$ & $1,3,5,7,9$ \\
\hline $\mathrm{V}_{\text {ref }^{+}}+\alpha$ & $1.7 \mathrm{~V}$ \\
\hline $\mathrm{V}_{\text {ref }^{-}}$ & $0.75 \mathrm{~V}$ \\
\hline system $\mathrm{CLK}_{\mathrm{CLK}}$ & $33.3 \mathrm{MHz}$ \\
\hline
\end{tabular}

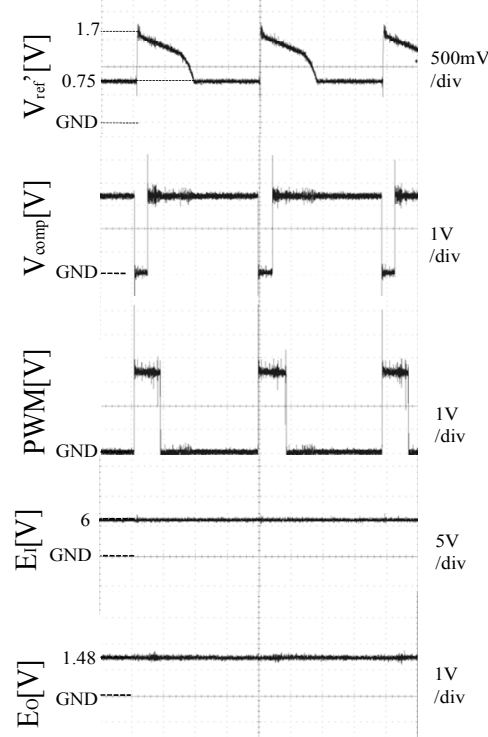

Fig. 5 Experimental waveforms pulse waveforms shown at the bottom of Fig.9 are calculated DPWM of FPGA. Fig. 9 shows the sudden load current increasing result. From this result, after the $1 \mu \mathrm{s}$ voltage drop, the output voltage immediately recovers to the reference voltage. Fig. 10 shows the sudden load current decreasing result. From this result, after the $1 \mu$ s voltage rising, the output voltage immediately recovers to the reference voltage.

\section{SUMMARY}

In this paper, the piecewise linear output voltage detection method for the proposed DPWM-POL is proposed. From the experiment results, the steady control and the fast response to load changes was confirmed.

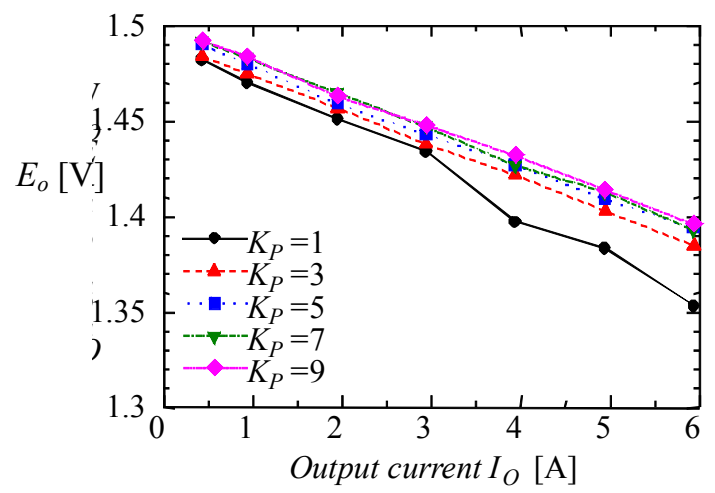

Fig. $6 I_{O}-E_{O}$ Characteristics
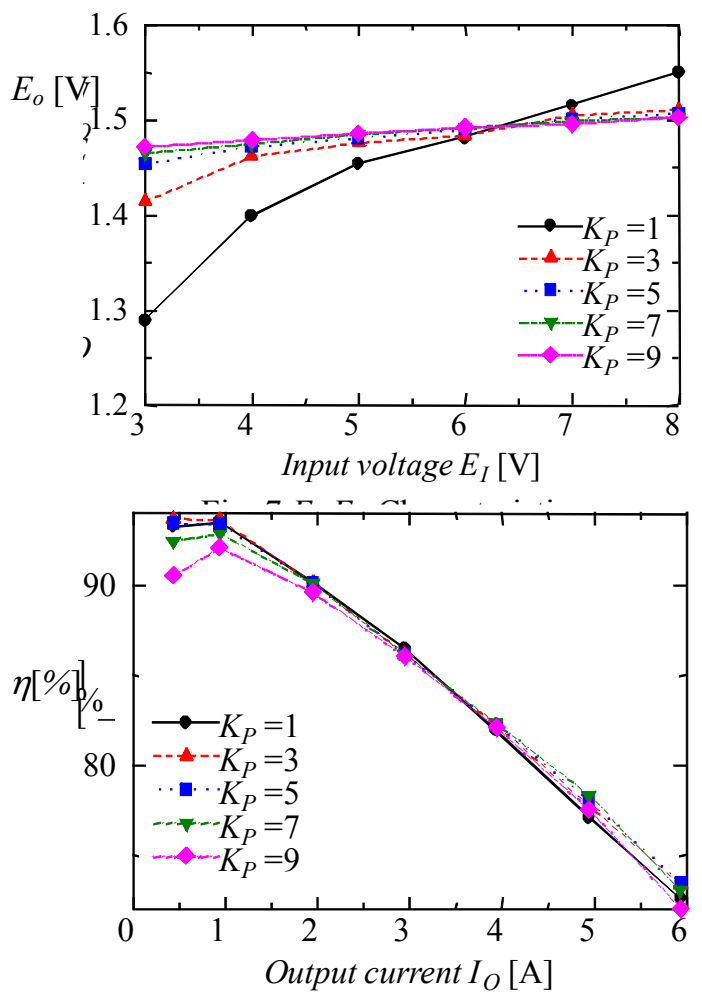

Fig. $8 I_{O^{-}} \eta$ Characteristics 
10.3

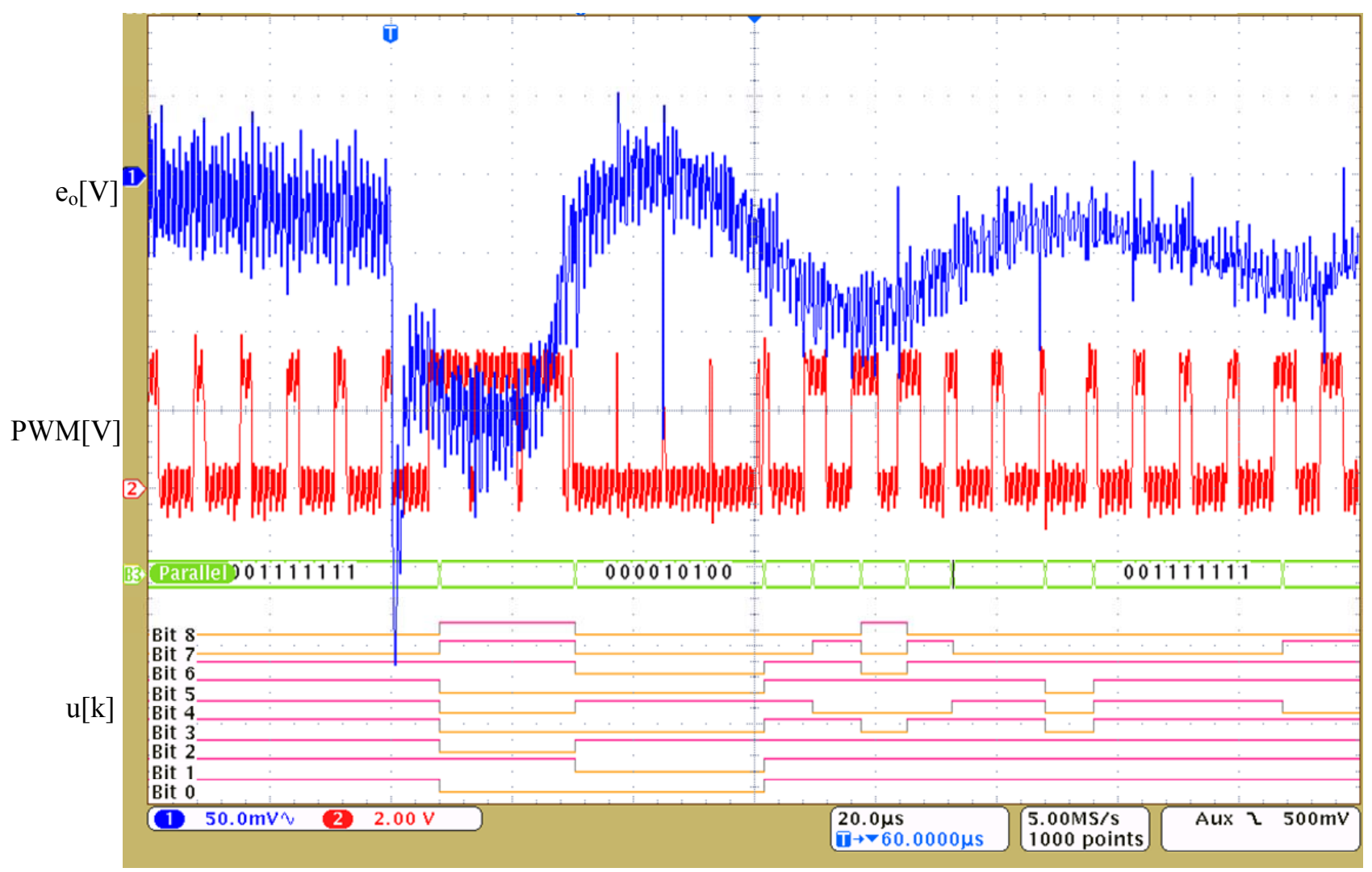

(a) $\mathrm{H}: 20 \mu \mathrm{s} / \mathrm{div}$.

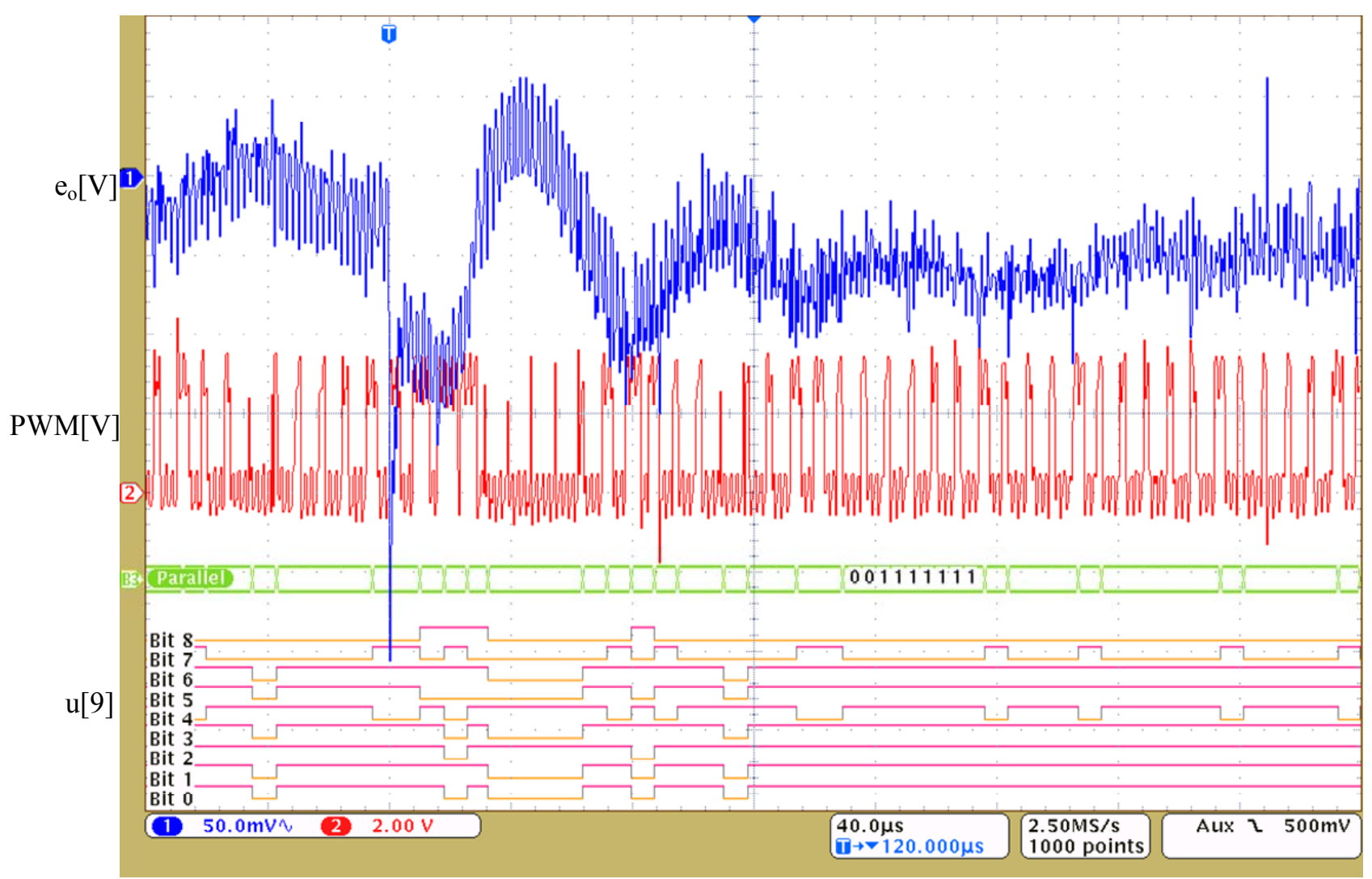

(b) $\mathrm{H}: 40 \mu \mathrm{s} / \mathrm{div}$.

Fig. 9 Dynamic characteristics (from $0.5 \mathrm{~A}$ to $5 \mathrm{~A}$ ) 


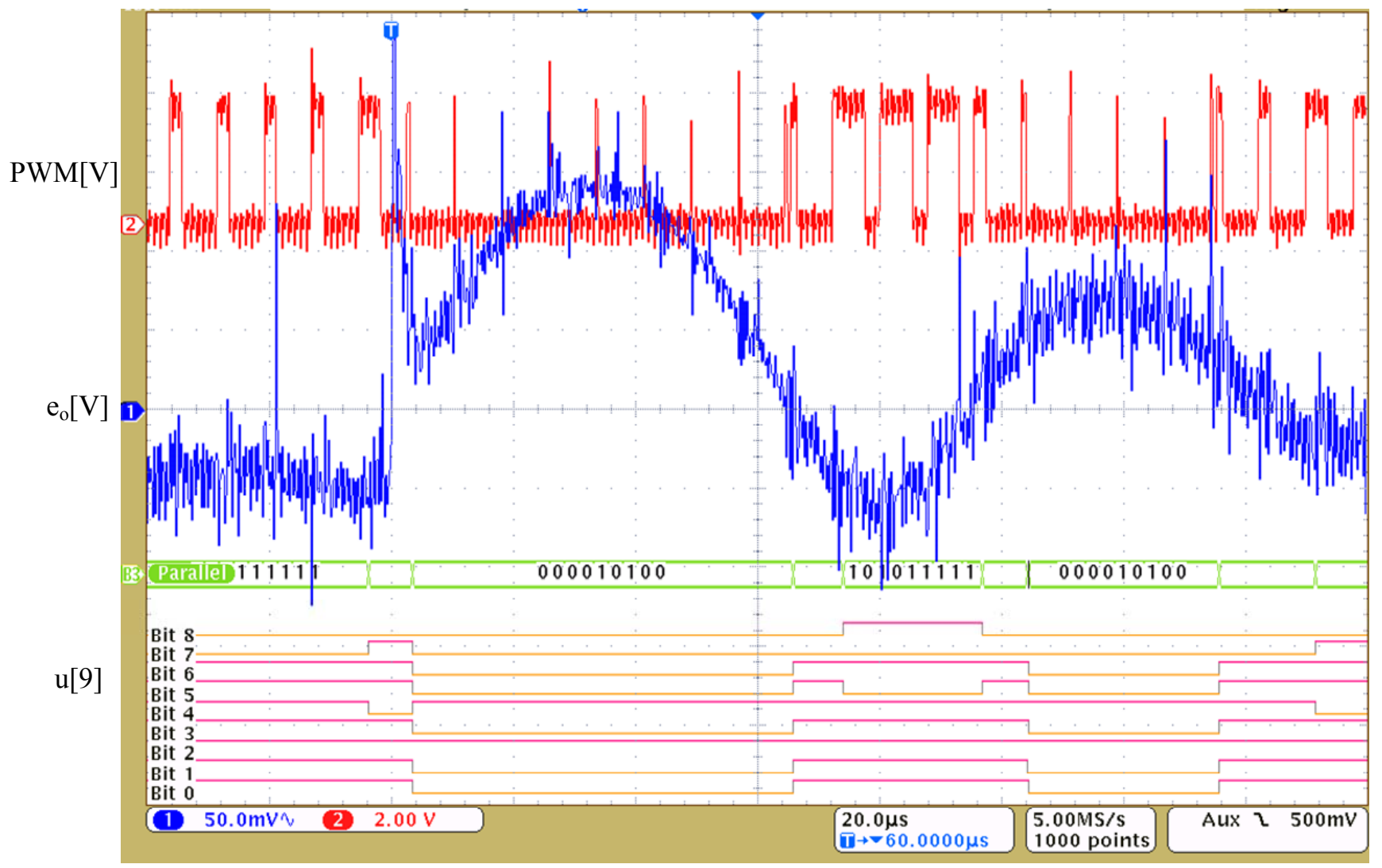

(a) $\mathrm{H}: 20 \mu \mathrm{s} / \mathrm{div}$.

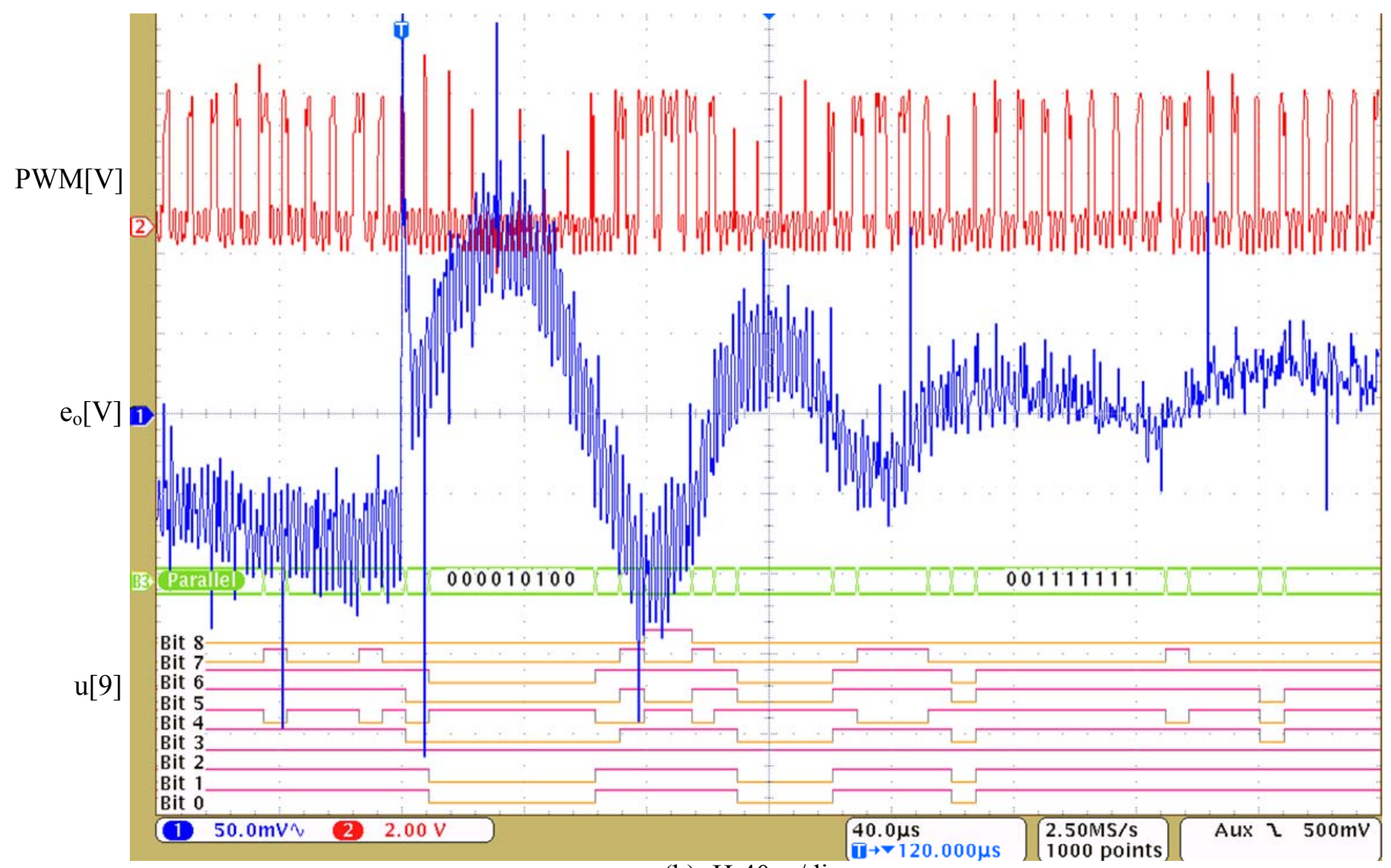

(b) $\mathrm{H}: 40 \mu \mathrm{s} / \mathrm{div}$.

Fig.10 Dynamic characteristics (from 5A to $0.5 \mathrm{~A}$ ) 


\section{REFERENCES}

[1] Akira Ichinose, Yoichi Ishizuka, Hirofumi Matsuo, "A Fast Response DC-DC Converter with Digital Pulse Width”, IEICE vol. 105, no. 538, EE2005-58, pp. 67-71, January 2006.

[2] Yoichi Ishizuka, Masao Ueno, Ichiro Nishikawa, Akira Ichinose and Hirofumi Matsuo, "A Low-Delay Digital PWM Control Circuit for DC-DC Converters, "22nd Annual IEEE Applied Power Electronics Conference and Exposition, Anaheim, CA, USA, 15.7, pp.579-586 , 2007. 2

[3] Mariko Nishi, Yosuke Asako, Yoichi Ishizuka, Hirofumi Matsuo, "A control circuit composition and several characteristics of the proposed DPWM controlled POL", IEICE, vol. 107, no. 430, EE2007-46, pp. 13-18, January 2008.

[4] Edward Lam, Robert Bell and Donald Ashley, "Revolutionary Advances in Distributed Power Systems, " in Proc. IEEE APEC '03, 1.5, 2003.

[5] Angel V. Peterchev and Seth R. Sanders, "Quantization Resolution and Limit Cycling in Digitally Controlled PWM, IEEE Trans. Power Electronics, Vol. 18 No. 1, pp.301-308, January 2003.

[6] V. Peterchev, S. R. Sanders, "Quantization resolution and limit cycling in digitally controlled PWM converters", IEEE Transactions on Power Electronics, Vol. 18, No. 1, January 2003, pp. 301 - 308.

[7] B.J. Patella, A. Prodic, A. Zirger, D. Maksimovic, "High-frequency digital PWM controller IC for DC-DC converters", IEEE Transactions on Power Electronics, Vol. 18, January 2003.

[8] D. Maksimovic, R. Zane, R. Erickson, "Impact of Digital Control in Power Electronics", IEEE International Symposium on Power Semiconductor Devices \& ICs, Kitakyushu, Japan, May 2004, pp. 13-22.

[9] Kaiwei Yao "High-Frequency and High-Performance VRM Design for the Next Generation of Processors", Doctor thesis of Virginia Polytechnic Institute and State University, April 14, 2004.

[10] S. Saggini, D. Trevisan, P. Mattavelli, "Hysteresis-Based MixedSignal Voltage-Mode Control for dc-dc Converters", IEEE Power Electronics Conference (PESC'07), Orlando, Florida, June 2007.

[11] S. Saggini, E. Orietti, P. Mattavelli, A. Pizzutelli, A. Bianco, "FullyDigital Hysteretic Voltage-Mode Control for dc-dc Converters based on Asynchronous Sampling", IEEE Applied Power Electronics Conference (APEC'08), Austin, Texas, February 2008.

[12] Gene F. Franklin, J. David Powell, and Michael L. Workman, Digital Control of Dynamic Systems, Addison Wesley Longman Press, Menlo Park. CA, 1997.

[13] Z. Zhao, S. Ahsanuzzaman, A. Prodic "ESR Zero Estimation and AutoCompensation in Digitally Controlled Buck Converters", IEEE Applied Power Electronics Conference (APEC'09), pp.247-251.

[14] Yu-Cheng Lin, Dan Chen, Yen-Tang Wang, Wei-Hsu Chang,

"A Novel Loop Gain Correction Method for DigitallyControlled DC-DC Power Converters", 2009 IEEE Energy Conversion Congress \& Expo pp3530-3535. 